\title{
Literatura infantil e textos informativos: conhecer e prevenir o COVID-19
}

\section{Children's literature and informative texts: knowing and preventing COVID-19}

\author{
${ }^{1}$ Vania Finholdt Angelo Leite vfaleite@uol.com.br
}

\section{RESUMO}

O relato de experiência escrito durante a pandemia reflete sobre ensinar e aprender em espaços não institucionais, nos lares e na convivência virtuais, uns com os outros, em 2020. Analiso 8 (oito) livros infantis que abordam a questão do coronavírus, sua forma de contágio e prevenção. Por meio dele, percebi que mesmo em casa, lendo livros e acessando outros materiais sobre conteúdos que são abordados na escola como a higiene, prevenção de doenças, vacinas, estamos sempre aprendendo. Embora não estejamos frequentando um espaço institucionalizado como a escola. Quanto aos 8 (oito) livros analisados, eles me proporcionaram refletir sobre o conhecimento científico que é construído em um contexto social e cultural, como resultado da construção humana. Ele é parte integrante da cultura, por isso, ele está presente em diversos setores, como na literatura infantil, artes, textos informativos. Por fim, enalteço o papel exercido pela leitura e destaco que a aprendizagem é contínua e ocorre em diferentes espaços, ao longo da vida.

Palavras-chave: Literatura Infantil. COVID-19. Ciências.

\begin{abstract}
The experience report written during the pandemic reflects on teaching and learning in non-institutional spaces, in homes and in virtual coexistence with each other in 2020. It focuses its analysis on 8 (eight) children's books that address the issue of coronavirus, its form contagion and prevention. Through it, I realized that even at home, reading books and accessing other materials on content that are covered in school, such as hygiene, disease prevention, vaccines, we are always learning. Although we are not attending an institutionalized space like the school. As for the 8 (eight) analyzed books, they allowed me to reflect on the scientific knowledge that is built in a social and cultural context, as a result of human construction. It is an integral part of culture, so it is present in several sectors, such as children's literature, arts, informative texts. Finally, I highlight the role played by reading and highlight that learning is continuous and occurs in different spaces, throughout life.
\end{abstract}

Keywords: Children's Literature. COVID-19. Sciences. 


\section{INTRODUÇÃO}

Aprender e ensinar em tempos de isolamento social está sendo um desafio para os pais, os educadores e as crianças. Como estamos afastados das escolas, porque não podemos ter grandes aglomerações por conta do contágio do vírus, tivemos que repensar e reinventar nossa rotina e nossa relação com os outros. Estamos sempre aprendendo, independente de a criança estar frequentando ou não uma escola ou instituição educativa. Parto do pressuposto de que aprendizagem é um fenômeno social que "não separa ação, pensamento, sentimento, valores e suas formas histórico-culturais e coletivas de atividades localizada, interessada, conflituosa e significativa” (LAVE, 2013, p. 238). Isso significa que aprender é parte integral das nossas vidas, por exemplo: quando o comentário de uma pessoa ou texto lido nos fornece um elo que faltava para a compreensão de um dado assunto. Neste caso, assim como em outros, visto que estamos sempre aprendendo, haveria necessidade de espaço institucionalizado?

Considero que ainda não há como nos dispensarmos de um espaço organizado, no qual as crianças tenham acesso aos conhecimentos organizados pela humanidade. No entanto, pondero que esses espaços precisam ser repensados de forma a proporcionar o envolvimento dos estudantes em "práticas significativas, de proporcionar acesso a recursos que promovam a participação deles, de abrir seus horizontes para que possam se colocar em trajetórias de aprendizagem com as quais se identifiquem” (WENGER, 2013, p. 253). Partindo dessa premissa, destaco que o envolvimento em projetos, discussões e reflexões mobilizam os estudantes no decorrer da ação educativa, instigando-os a participarem ativamente, fazendo a diferença na sociedade. Todavia, esta realidade ainda é bem diferente do que ocorre em muitas escolas brasileiras, que ao invés de instigarem à participação, procura manter o interesse do estudante pelo controle da nota e/ou vestibular.

Muitas escolas particulares passaram a oferecer um ensino remoto para manter a prestação de serviço, focando a ação na transmissão dos conteúdos programados na grade curricular. Além disso, como estamos em plena pandemia, fica uma indagação se as escolas não estão mais ensinando? Faço essa pergunta, porque o que vem ocorrendo é o envio de muitas tarefas para seus alunos que, juntamente com a sua família, dão continuidade ao programa. Discordo que a função da escola seja só a de transmitir conteúdos, porque a transferência dá uma ideia de depositar um conhecimento em quem o recebe, numa situação passiva. Concebo que ensinar, assim como Freire (1999, p. 52), consiste em “criar a possibilidade para a produção e criação do conhecimento" daquele que aprende, resultando num processo de criação e a autonomia por quem aprende, desenvolvendo sua capacidade crítica e sua curiosidade. (FREIRE, 1999).

Tendo como referência esses pressupostos, trago as minhas reflexões e experiências com leitura durante a pandemia do COVID-19 para refletir com os leitores sobre materiais direcionados às crianças sobre o vírus. Neste texto, analiso 8 (oito) livros dos seguintes autores: Baptista (2020), Campos (2020), Dellagiustina; Broering (2020); Leite (2020), Molina (2020), Nogueira (2020), Patuck (2020), Sato; Santos; Sánchez (2020). Levando em consideração que nestes tempos de afastamento social, em que muitas crianças ficaram sem acesso e possibilidade de continuar seus estudos presencialmente, tendo que se conectarem às mídias com diversos e diferentes fontes de materiais, me ponho diante da seguinte questão: quais oportunidades de aprendizagem tiveram em casa em contato com seus familiares?

Em março de 2020, durante o processo de afastamento social, tive tempo para pesquisar, ler, estudar e refletir sobre a situação vivenciada no Brasil e no Mundo, porque fiquei em casa como muitos brasileiros que não trabalhavam nos serviços essenciais.

Tive curiosidade de buscar materiais que pudessem informar as crianças sobre o que estava ocorrendo naquele momento. Os pais acumularam vários papéis durante o isolamento social, passaram a ser pais, professores de seus filhos, de trabalhadores em tempo integral. Como conciliar tudo isso? Como escolher um material adequado a necessidade de seus filhos?

No próximo tópico, vou apresentar a análise de livros literários e informativos que abordam a questão do Coronavírus. 


\section{HISTÓRIAS E TEXTOS INFORMATIVOS}

Reafirmo que em uma das buscas realizadas em abril de 2020, encontrei 8 (oito) livros infantis abordando o tema do COVID-19. No primeiro momento, fiquei surpresa pelo fato dos autores disponibilizarem todo esse material gratuitamente para que os pais e responsáveis pudessem ler com as crianças em casa. Essas ações de solidariedade foram aumentando no mês de abril 2020 no Brasil, as pessoas passaram a oferecer palestras, doações de alimentos, contação de histórias, serviços aos mais próximos. Juntar-se aos outros e ajudá-los tornou-se uma forma de sobrevivência e de enfrentamento da pandemia, situação que nos fez perceber o quanto a colaboração de todos pode fazer a diferença, no sentido de contribuir para minimizar com a dor do outro.

Estamos diante de um problema de difícil solução que requer a cooperação de várias pessoas e especialidades para solucioná-lo. Temos acompanhado cientistas de toda parte do mundo compartilhando pesquisas, estudando os remédios, elaborando vacinas, um fazer junto com o outro. Vale ressaltar que antes da pandemia já tínhamos Organizações Não Governamentais e outras formas de compartilhamentos e trocas com o outro, mas que foram expandidas nesse momento.

Retomando aos livros encontrados, desses oito, dois são informativos, cinco são contos e uma carta. O fato dos autores recorrerem aos gêneros literários, além de ser essencial nesse momento, reforçam o quanto "a leitura literária é essencial para e na formação humana, ao ler o indivíduo interage não apenas com a palavra escrita, mas com outras experiências, portanto, ler conduz ao encontro com os outros e consigo mesmo" (VENTURA, CHALUH, 2018, p. 486).

No segundo momento, fiz uma leitura mais cuidadosa dos livros, buscando responder às seguintes questões: a) quais são os personagens? b) qual a relação entre fantasia e informação? c) o que nos provoca a ilustração?

Quanto aos personagens, cinco desses livros têm a criança ou as pessoas como heróis da história. São os seguintes: 1) "O vírus malvadão e as crianças poderosas" (CAMPOS, 2020); 2) A máscara dos sentimentos (DELLAGIUSTINA; BROERING, 2020); 3) Sofia e OTTO: Somos Heróis. Os cuidados para o coronavírus ir embora (LEITE, 2020); 4) Meu nome é Coronavírus (MOLINA, 2020); 5) Meu Herói és Tu: como as crianças podem combater o COVID-19 (PATUCK, 2020).

Nesses livros, o vilão é o vírus que ataca aqueles que não atendem as recomendações de proteção (isolamento social e higiene pessoal/local). A orientação vem de forma poética pelos autores, é uma maneira de sensibilizar as crianças para seguirem e engajar-se nos cuidados, como por exemplo nas palavras de Leite (2020, p. 12) "mas, não usaremos armas, nem superpoderes para atacar este vilão. Ao invés de atacar, iremos nos defender”. Este autor sugere ao leitor a não violência, mas ficar na defensiva para se proteger do vírus. Complemento essa recomendação com a orientação de Patuck (2020, p.19) que escreveu: “Às vezes, a coisa mais importante que podemos fazer como amigos é proteger um ao outro - disse Ário. Mesmo que isso signifique estar longe um do outro por um tempo". Patuck aborda a questão do afastamento das pessoas que gostamos como forma de proteção.

Reafirmo que nos 5 (cinco) livros, o fato do ser humano ser o herói, contribuiu para que o leitor dessas histórias pudesse se identificar com o personagem, facilitando a adesão às prevenções necessárias para não se contaminar, assim como fortalecer-se para lidar com seus medos perante ao vírus. Leite (2020, p.10) escreve que "todos nós podemos ser os verdadeiros heróis nessa história. [...] a prevenção é o melhor jeito para acabar com o malvado Coronavírus!”

Em outro livro, Baptista (2020, p. 9) coloca para as crianças de seu livro, que todos são heróis, aqueles que estão em casa e os que precisam sair para trabalhar: "fazendo a nossa parte somos também heróis, como os supermédicos, as supermédicas, as superenfermeiras, os superenfermeiros, o superporteiro do hospital”.

Nas entrelinhas Baptista vai mostrando que os prestadores de serviços essenciais são super-heróis, porque estão saindo para que nós possamos ficar em casa em segurança. Aqui cabe uma crítica, porque esses livros estão 
direcionados para crianças de uma classe social mais favorecida. Aquelas que moram na periferia da cidade nem sempre conseguem manter o isolamento na sua casa, nem conseguem cumprir com a prevenção básica de lavar as mãos pela falta de saneamento básico.

Acerca da relação entre a fantasia e a imaginação, dois livros me sensibilizaram durante a leitura, porque me reportaram ao mundo da fantasia, ao mesmo tempo, que aprendia a enfrentar o Coronavírus. Nesses dois livros há um equilíbrio entre as informações científicas e a fantasia característica do mundo infantil. É o que apontam Pereira e Balça (2018) ao afirmarem que "a literatura precisa cruzar com o prazer com as emoções, isso significa inspirar e informar; nutrir nossa imaginação e emoções” (p.123).

O primeiro é o de Patuck (2020) que narra a história de duas personagens negras, Sara e sua mãe científica. A história inicia com a conversa de Sara e sua mãe sobre o Coronavírus, dando vida ao enredo que se passa durante o sonho de Sara, no qual ela defronta com seus medos e formas de enfrentar o vírus. Ela não se sentia com um superpoder para encarar toda a situação vivenciada, quando, então, aparece Ário - um bicho que a leva para falar com outras crianças pelo mundo. Nessa viagem, ela vai aprendendo como cada uma como lidar com os sentimentos. $\mathrm{O}$ fato de Patuck apresentar os superpoderes de cada ser humano da história, mesmo aqueles que se sentem fragilizados, mostra à criança o que ela poderá fazer para enfrentar o COVID-19, dando-lhe um "poder" para encarar seus sentimentos ambíguos nesse momento de pandemia.

Patuck (2020), ao trazer personagens negras, sendo uma delas uma cientista - provoca o leitor a refletir e repensar os valores da cultura eurocêntrica branca, cristã e ocidental. É uma forma de instigá-lo a rever seus estereótipos e padrões. Ao ler a história, o leitor se depara com as pessoas negras que têm acesso ao conhecimento e aos bens culturais. É uma oportunidade para ele se questionar e se posicionar contra o racismo, instigando-os a lutar para que todos tenham acesso ao conhecimento e aos bens culturais, de saúde, dentre outros. Temos na sociedade brasileira muita desigualdade entre brancos e negros, com estes últimos ainda em desvantagens. Neste sentido, a pandemia vem nos mostrando que, no Brasil e no mundo, o vírus incurável é o racismo, pois na medida que o COVID-19 avança, expõe as desigualdades históricas que fizeram os negros mais vulneráveis e socialmente invisíveis. Por isso, esse livro é essencial para leitura de todos.

O livro organizado por Baptista (2020) é uma carta direcionada aos meninos e às meninas. As informações vêm de forma clara e objetiva, como por exemplo: “Antes de chegar no Brasil, essa doença viajou por outros países, como China, Itália, Espanha, França, Estados Unidos, Canadá, Irã. Hoje se espalhou pelo mundo todo. Por isso, é chamada de pandemia” (BAPTISTA, 2020, p. 6). A cada página do livro, o leitor é surpreendido por uma ilustração diferente de famosos artistas, dentre eles: Alexandre Rampazo, Anna Cunha, Camilo Martins, Elisa Carareto, Gabriel Benedito, Graça Lima, Luiz Silva, Marilda Castanha, Nelson Cruz, Odilon Moraes e Raquel Matsushita. Cada um desses artistas tem um estilo que nos toca por sua maneira de expressar através das ilustrações.

O que me encantou nesses dois livros é que eles me possibilitaram enquanto leitora "identificar e projetar meus medos e desejos nas tramas com seus personagens” (ROSA, 2009, p.2). Concordo com Rosa (2009, p. 2) que a história é pertinente à criança, "quando ela lhe diz algo de si mesma, que nos mostre o que a criança - ou os pais - está calando". Os livros me possibilitaram perceber meus sentimentos, que na pandemia estão me mobilizando constantemente. Enfrentamos medo pelo desconhecido, pelo imprevisto, pela incerteza, pelo que virá no futuro e tantos outros.

Ainda a respeito dos livros, 3 (três) deles, o de Campos (2020), Dellagiustina; Broering (2020) e de Molina (2020) propõem que a criança expresse seu sentimento através do desenho. Sendo que o de Campos solicita que a criança desenhe como ela imagina o vírus. Os outros dois, solicitam que ela expresse seus sentimentos pela pintura de máscaras, e o outro desenhando seu rosto. Ao solicitar que o leitor desenhe e pinte, possibilita-o trazer para fora os seus sentimentos para que não paralise a pessoa a ponto de não conseguir fazer mais nada. É necessário para nossa saúde expressar nossos sentimentos, colocá-los para fora, não guardá-los para que não criem abscessos, tumores, nódulos, pedras. Por isso, a importância desses livros com propostas de desenhos, 
pinturas, porque essas propostas de expressar-se através da arte possibilitam a criança mostrar, escrever e falar sobre seus sentimentos nesse momento pandemia.

No livro escrito por Molina (2020), o narrador é o próprio vírus. É interessante proporcionar ao leitor uma reflexão sobre a concepção do vírus. A história começa com "Adoro viajar... e pular nas mãos das pessoas para cumprimentar" (MOLINA, 2020, p. 2). Mostra a criança que pelo contato com o outro o vírus pode ser transmitido. Usa de uma linguagem clara, objetiva e poética para transmitir o cuidado necessário para se prevenir do vírus. Além da informação de prevenção, proporciona ao leitor encarar seus sentimentos, trazendo o questionamento: “E como você se sente quando escuta o meu nome?” (MOLINA, 2020, p. 3). O narrador tenta tranquilizar as crianças dizendo: "pode ficar tranquilo! Os adultos que cuidam de você: Vão mantê-los seguro" (MOLINA, 2020, p. 9). Infelizmente, não é verdade para todas as crianças que terão acesso ao livro.

Quanto aos dois livros informativos de divulgação científica, escritos por Nogueira (2020) e Sato, Santos e Sánchez (2020) apoiei nas sugestões de Torok (2009), para analisá-los. A escolha do texto de Torok (2009) para apoiar nessa análise, se deve ao fato da experiência do autor na divulgação científica para público infanto-juvenil. Ele foi editor da revista The Helix e Scientriffic.

Para Torok (2009), o texto de divulgação científica para jovens e crianças apresenta as seguintes características: a) linguagem clara, concisa e criativa; b) analogias apropriadas para faixa etária; c) personagem com o qual o jovem possa admirá-lo; d) descrever a ciência em desenvolvimento com problemas ainda sem solução, desafiando o jovem leitor; e) levar em conta o que o público gostaria de saber.

O livro organizado por Nogueira et al (2020) denominado de “Coronavírus” é destinado a crianças do nível de alfabetização com leituras de textos informativos. A estrutura dos textos é objetiva, como na definição dos autores: "os coronavírus fazem parte de um grupo de seres minúsculos chamados de microorganismos. Eles são tão minúsculos que precisamos de um microscópio para vê-los” (NOGUEIRA et al, 2020, p. 1). No texto, os autores fazem analogias do cotidiano das crianças, como por exemplo, para explicar o que é o material genético da célula associam ao chip do celular que "é aquele que contém as informações sobre o que o vírus deve fazer" (NOGUEIRA et al, 2020, p. 6). Outra analogia interessante, é a fábrica de copiar vírus (local onde o coronavírus usa para replicar-se) - que é a célula do hospedeiro, nesse caso, nós humanos. Os autores mostram para as crianças os microorganismos bons e os ruins, associando os primeiros aos super-heróis, com escudo e espada, e os últimos aos vilões que são bichos feios com fisionomia de malvados e muito assustadores.

Nogueira et al (2020) mostram aos leitores que ainda não se sabe tudo do coronavírus e que o conhecimento científico é provisório, ou seja, está em permanente construção. Isso fica evidente na afirmação "É possível que o SARS-COV-2 tenha sido transmitido de morcegos para outro hospedeiro animal” (p. 11). Enfim, é um livro informativo que traz uma mensagem/linguagem pertinente para a criança em processo de alfabetização, sem menosprezar a inteligência e perspicácia das crianças.

O outro livro informativo, "Vírus: Simulacro da vida?" escrito por Sato; Santos e Sánchez (2020) não deixa claro qual é o público alvo. Depois da leitura, eu diria que é para as crianças e jovens curiosos e inquietos, aqueles que não se contentam com uma simples explicação. Cheguei a essa conclusão, porque os autores desafiam os leitores a refletirem a partir do título. Para quem está interessado sobre o que é simulacro, os autores definem: "uma mera imitação da vida, um espectro ainda sem compreensão" (SATO; SANTOS; SÁNCHEZ, 2020, p. 4). Logo a seguir, eles lançam outro desafio ao leitor: "Mas... se o vírus não tem vida, por que existe a recomendação de usar álcool gel, ou sabão para “matá-lo”?” (ibidem, p. 4). É um texto com muita criatividade na forma de transmitir a mensagem e informação para o leitor.

Quanto às analogias, os autores utilizaram a da máquina e da linha de montagem para explicar sobre a reprodução do vírus. Eles escreveram: "O vírus usa táticas de disfarces para se reproduzir e tem uma linha de montagem invejável a qualquer indústria automobilística” (ibidem, p. 5). O livro não personaliza o vírus, assim 
como o livro de Nogueira et al (2020). Os autores mostram ao leitor que a ciência está em desenvolvimento e evolução, como por exemplo: "No início da pandemia, acreditava-se que o Coronavírus tinha o pangolim como hospedeiro, mas recentes estudos avaliam que o pangolim é só o intermediário entre uma espécie de morcego ferradura e o humano" (ibidem, p. 60). É um livro muito interessante, instigante e reflexivo! Vai além das discussões de apresentar o vírus, sua forma de contágio e prevenção. Os autores apontam a causa de tantas epidemias na sociedade e destacam que

A destruição da natureza e os desequilíbrios ecológicos são alguns dos fatores que mais contribuem para aumentar a proliferação de doenças causadas por vírus. Isso porque eles vivem em animais silvestres (hospedeiros) e com o aumento das populações humanas invadindo áreas naturais, cada vez mais se tem a possibilidade de contato com vírus (ibidem, p.9).

[...] Crise climática, pandemias, banalização da vida e capitalismo são faces de uma civilização em plena crise, que parece não querer aprender com esta lição chamada Covid-19’ (ibidem, p. 11).

Somos os causadores dos desequilíbrios ecológicos, porque priorizando o ter, o consumismo, a produção desenfreada, ao invés de escolhermos cuidar da floresta, dos animais, do ecossistema. Estamos percebendo que somos ecodependentes nesse planeta, se um elo dessa cadeia entra em desequilíbrio todos sofreremos as consequências. Caberá, portanto, a busca de alternativas sustentáveis e solidárias, a partir de uma compreensão ecopolítica da realidade. Sendo assim, precisaremos pensar na complexidade da vida no planeta, pois como tudo e todos estamos em constante relação, não será em uma única área que encontraremos a solução.

\section{PALAVRAS FINAIS...}

Retomando a questão básica desse relato de experiência reflexivo, isto é, sobre o ensinar e aprender durante a pandemia em muitos lares, sobretudo aqueles mais desfavorecidos. Afirmo que diante de um problema tão complexo, parece que fomos colocados em frente de uma lupa de aumento. Tudo ficou mais acelerado diante de todos nós.

Percebemos que estamos sempre aprendendo, mesmo não frequentando um espaço institucionalizado como a escola. Aprendemos, mesmo em casa, sobre conteúdos que são abordados na escola como a higiene, prevenção de doenças, vacinas etc. Além desses conteúdos, aprendemos o quanto é essencial a cooperação entre as diferentes especialidades. Cientistas, biólogos, geneticistas, médicos, enfermeiros, farmacêuticos, entregadores cada um tem algo a contribuir para enfrentar o COVID-19. Na área médica, o diálogo entre as diferentes áreas e os diferentes países é essencial para entender o vírus e buscar um remédio ou uma vacina. Para tanto, a perspectiva multidisciplinar tem se mostrado fundamental para enfrentar a pandemia e para a busca da solução de problemas sanitários, de saúde e da economia.

Quanto aos livros analisados, percebemos que o conhecimento é construído quando temos acesso a literatura, artes, textos informativos e jornalísticos. Enfim, não há uma única forma de obtê-lo, mas as diferentes linguagens nos possibilitam agir, tomar decisões e compreender o que está em jogo no discurso dos especialistas e da mídia.

Dos 6 (seis) livros literatura infantil analisados, o foco está centrado no indivíduo e na prevenção. Os autores ressaltam essa mensagem utilizando uma linguagem poética, cativante, envolvente para que o leitor mude seu comportamento. Destaco que esses livros cumpriram sua função, porque me oportunizou enquanto leitora me emocionar, deliciar com as ilustrações e linguagens provocando, uma empatia entre os personagens e o leitor, para auxiliá-lo a vivenciar o momento de isolamento social.

Já os dois livros informativos, esclareceram o leitor sobre o vírus, sua transmissão e prevenção através da linguagem informativa, clara e objetiva. Os autores do livro "Vírus: Simulacro da vida" trazem uma perspectiva de ciência relacionando a explicação científica, o contexto social e os valores de cada um na tomada de 
decisão. Eles levantam questionamentos em relação a ordem capitalista e os valores econômicos que se impõem nas decisões de muitos na nossa sociedade. Ao mesmo tempo que fazem esses questionamentos, acrescentam outros, como os vinculados aos interesses coletivos de compromisso social, de reciprocidade e respeito ao outro. Termino o texto, com a frase de Sato; Santos; Sánchez (2020, p. 13):

A pandemia nos mostra que ninguém se cura sozinho e que não adianta só você se curar isoladamente - é uma pandemia que tem muito a nos ensinar sobre a nossa própria humanidade e a nossa profunda interdependência com todos os seres do planeta, além de nos lembrar de nossa imensa fragilidade. Um vírus foi capaz de parar o planeta.

Portanto, os 8 (oito) livros analisados me proporcionaram refletir sobre o conhecimento científico que é construído em um contexto social e cultural, enquanto resultado da construção humana. Ele é parte integrante da cultura, por isso, identificamos sua presença em diversos setores, como na literatura infantil, artes, textos informativos. Assim, eles reiteram a nossa ideia de que a aprendizagem é contínua e ocorre em diferentes espaços, ao longo da vida.

\section{REFERÊNCIAS}

BAPTISTA, Mônica Correia. (ORG). Carta às meninas e aos meninos. Em tempos de COVID-19. Fórum Mineiro de Educação Infantil. Março de 2020.

CAMPOS, Daniel Cavalcanti. O vírus malvadão e as crianças poderosas. Aveiro, Portugal. Março, 2020.

DELlAGIUSTINA, Ana Paula Garcia; BROERING, Camila Volpato. A máscara dos sentimentos. Abril 2020.

FREIRE, Paulo. Pedagogia da autonomia: saberes necessários à prática educativa. $12^{\mathrm{a}}$ ed. São Paulo: Paz e Terra, 1999.

LAVE, Jean. A prática da aprendizagem. IN: ILLERIS, Knud (org). Teorias contemporâneas da aprendizagem. Porto Alegre: Penso, 2013. p.235-245.

LEITE, Pedro. Sofia e OTTO: Somos Heróis. Os cuidados para o coronavírus ir embora. Editora: PGL. Acesso em: 0404 20. Disponível em: <www.sofiaotto.com.br >.

MASSARANI, Luisa (ed.). Ciência e criança: a divulgação científica para o público infantojuvenil / Editado por Luisa Massarani. - Rio de Janeiro: Museu da Vida / Casa de Oswaldo Cruz / Fiocruz, 2008.

MOLINA, Maunela. Meu nome é Coronavírus. Mindheart International public License. 2020. Disponível em: < www.mindheart. Co/descargables> Acesso em: 5 abr 2020.

NOGUEIRA, Roberta M.; DONOFRIO, Fabiana C.; PIRES, Evaldo M.; BRONZONI, Roberta V.M.; SOCREPPA, Leticiane M. Coronavírus. Cuiabá: Fundação UNISELVA, 2020. Série Pequenos Cientistas: Mundo Invisível - MT Ciências. Disponível em: < https://sobep.org.br/wp-content/uploads/2020/04/Coronav\%C3\%ADrusS\%C3\%A9rie-Pequenos-Cientistas.pdf $>$.

PATUCK, Helen. Meu Herói és Tu: como as crianças podem combater o COVID-19. IASC, 2020. Disponível em: < https://interagencystandingcommittee.org/system/files/2020-04/My\%20Hero\%20is\%20You\%2C\%20 Storybook\%20for\%20Children\%20on\%20COVID-19\%20\%28Portuguese\%29.pdf >.

PEREIRA, Claudia; BALÇA, Angela. Educação literária na escola: a importância da escolha do livro e das atividades para a sua exploração na sala de aula. Educação em Análise., Londrina, v.3, n.1, p. 113-132, JAN./ JUN. 2018. 
ROSA, Daniela da. A infância contemporânea e seus heróis. UFAL. ANAIS do XV Encontro Nacional da Associação Brasileira de Psicologia Social. Maceió, AL, 2009.p. 1-7.

SATO, Michèle; SANTOS, Déborah M; SÁNCHEZ, Celso. Vírus: Simulacro da vida? Rio de Janeiro: GEASUR, UNIRIO, 2020 Cuiabá: GPEA, UFMT, 2020.Cuiabá: GPEA, UFMT, 2020.

TOROK, Simon. Falar de ciências para crianças: algumas dicas. IN: MASSARANI, Luisa (ed). Ciência e criança: a divulgação científica para o público infanto-juvenil. Rio de Janeiro: Museu da Vida/Casa de Oswaldo Cruz/Fiocruz, 2008. p.50 - 55.

VENTURA, Fabiana Cristina; CHALUH, Laura Noemi. Crianças e literatura: múltiplos encantos. Ensino em Re-Vista. Uberlândia, MG. V.25, n.2, p.486-505, maio/ag.2018.

WENGER, Etienne. Uma teoria social da aprendizagem. IN: IN: ILLERIS, Knud (org). Teorias contemporâneas da aprendizagem. Porto Alegre: Penso, 2013. p.246-257. 